\title{
Proposing a model for absorption capacity of technology
}

\author{
H.Gholizadeh $^{1} *$, A.Bonyadi Naeini ${ }^{2}$, A.Moini $^{2}$ \\ ${ }^{1}$ Department of Progress Engineering, Iran University of Science and Technology, Ave. Narmak, 16846-13114-Tehran, Iran \\ ${ }^{2}$ Assistant Professor, Department of Progress Engineering, Iran University of Science and Technology, Narmak, Tehran, Iran \\ *Corresponding author E-mail: Hossein_gholizadeh@ind.iust.ac.ir
}

Copyright (ㅇ 2015 H.Gholizadeh et al. This is an open access article distributed under the Creative Commons Attribution License, which permits unrestricted use, distribution, and reproduction in any medium, provided the original work is properly cited.

\begin{abstract}
Absorption capacity of knowledge is the concept which is been introduced in this situation. This phenomenon describes why some countries are in a better condition with a view to technology. Many countries believe that the power to stay in the battle and excel other competitors directly depends on their abilities in taking knowledge. Many countries have used their technological gap with developed countries as an accelerator for improving their absorption capacity. In this study, authors tried to produce a complete definition for absorption capacity through analyzing different research. Then with using expert opinions, a categorization for dimensions of absorption capacity will be prepared by using the structural equation modeling analysis, and finally a model for measuring absorption capacity is suggested. The results show effective dimensions in 5 different section. Studies depict that the most important one is keeping which could be a fundamental for long-term policies of 1404 .
\end{abstract}

Keywords: Absorptive Capacity; Innovation; Structural Equation Model; Nanotechnology; Knowledge.

\section{Introduction}

Today, competitive advantage is more affected by the available knowledge than it is dependent on physical resources because physical assets alone cannot provide competitive advantage like before despite two characteristics of ambiguity and complexity in new business environments. There are knowledge resources beyond the hypothetical boundaries and competitive capabilities can be developed by using and exploiting them [1]. Absorptive capacity refers to ability to put new ideas and combine them in internal processes and this ability has been widely considered as one of the main performance factors $[2,3]$. Today, ability to detect value of new things, external information, absorb, adapt and apply them is important and vital for commercial purposes for the innovation activities and plays important role in development of innovation advantages and flexibility It is necessary to note that ability to evaluate and use the external knowledge is dependent on knowledge resources, primary knowledge level and ability of the enterprise or country to consider the external knowledge.

Absorptive capacity means learning of the environment which is a type of learning which pays attention to learning of knowledge resources in the environment instead of emphasis on value creation through experience [7-9]. Theoretically, concept of the absorptive capacity is common among some issues such as dynamic capabilities [10], organizational learning and knowledge management [11]. The researches were conducted on absorptive capacity dominated by the quantitative studies which investigated specifications, factors and dynamicity in terms of absorptive capacity [12], [13]. In recent studies, the approach was toward studies of innovation networks and knowledge transfer in coalitions. However, few studies have investigated the internal processes of absorptive capacity [14].

Concept of absorptive capacity has been widely applied for analysis of innovation processes and effect of learning on creation of competitive advantage but it has been prevented from creation of stable body of theoretical knowledge, recognition of the effective factors and main actors and components and results [15], [16]. 


\section{Place of absorptive capacity in definitions}

To know place of absorptive capacity, place of absorptive capacity can be specified in the known concepts of the technology management. In studies by Lin, four research flows have been mentioned with strong overlap with absorptive capacity [13], [17].

Table 1: Place of Absorptive Capacity

\begin{tabular}{llll}
\hline & Knowledge identification & Knowledge protection & Knowledge utilization \\
\hline Internal & Creative capacity & Transformational capacity & Innovative capacities \\
External & Absorptive capacity & Binding capacity & Repulsive capacity \\
\hline
\end{tabular}

Table 2: Research Flow with Strong Overlap with Absorptive Capacity

\begin{tabular}{ll}
\hline Strategic unity & Organizational learning \\
\hline Resources based attitude & Knowledge management \\
\hline
\end{tabular}

\section{The studied levels of absorptive capacity in the researches}

The studied levels in researches of absorptive capacity which have been collected in the following Table show orientation of the researches. The reason for orientation of the researches on absorptive capacity on the enterprises levels are the expressible need and payment of financial costs in this level of researches.

Table 3: The Studied Levels of Absorptive Capacity in Researches [13], [18-20]

\begin{tabular}{ll}
\hline The studied levels & Writer \\
\hline Individual & Cohen \& Levinthal, 1990 \\
Cooperation among people & Malhotra, Gosain, and El Saw, 2005 \\
Business units & Szulanski, 1996 \\
Organizational & Cohen and Levinthal, 1990 \\
Paired & Lane and Lubatkin, 1998, Lane et al., 2001 \\
Cluster-based & Giuliani, 2003; Giuliani and Bell, 2005 \\
Industrial blocks & Aage, 2003 \\
& Criscuolo and Narula, 2008 \\
State and national & Dahlman and Nelson, 1995 \\
& Mower and Oxley, 1995 \\
& Kedia and Bhagat, 1998 \\
\hline
\end{tabular}

\begin{tabular}{|c|c|}
\hline Writer & Definition \\
\hline Alen, 1984 & $\begin{array}{l}\text { He has defined absorptive capacity as result of research and development efforts to use extern al } \\
\text { knowledge. }\end{array}$ \\
\hline $\begin{array}{l}\text { Cohen and } \\
\text { Levinthal, } 1989\end{array}$ & $\begin{array}{l}\text { They defined absorptive capacity as learning ability through processes of identification, absorption } \\
\text { and utilization of external knowledge. }\end{array}$ \\
\hline $\begin{array}{l}\text { Cohen and } \\
\text { Levinthal, } 1990\end{array}$ & $\begin{array}{l}\text { They introduced absorptive capacity as ability of an organization to recognize values and external } \\
\text { information, absorb and commercialize it which is dependent on the previous knowledge , } \\
\text { diversity and extent of knowledge base, experience, learning, common language, mutual relations, } \\
\text { subjective models, the presence of human force with ability to solve problem. }\end{array}$ \\
\hline $\begin{array}{l}\text { Lichtenthaler, } \\
2009\end{array}$ & $\begin{array}{l}\text { Absorptive capacity is the ability of a company to use external knowledge through combined } \\
\text { processes of exploration, change, learning and utilization. }\end{array}$ \\
\hline $\begin{array}{l}\text { Teece ‘Shuen ، } \\
1997\end{array}$ & $\begin{array}{l}\text { Absorptive capacity is defined as a vital factor and intangible source which have increased } \\
\text { performance of the company and brought competitive advantage for the organization. }\end{array}$ \\
\hline $\begin{array}{l}\text { Lane and } \\
\text { Lubatkin } 1998\end{array}$ & $\begin{array}{l}\text { They have defined ability to recognize value, absorb and use the acquired knowledge from another } \\
\text { organization and they were the first scientists who introduced reinterpretation of Cohen and } \\
\text { Levinthal's structure. Absorptive capacity was introduced as knowledge absorption from other } \\
\text { sections but Lin and Lubatkin introduced absorptive capacity as absorption from other } \\
\text { organizations. }\end{array}$ \\
\hline $\begin{array}{l}\text { Van den Bosch et } \\
\text { al. } 1999\end{array}$ & $\begin{array}{l}\text { They have defined absorptive capacity as including evaluation, acquisition, integration and } \\
\text { commercial use of new external knowledge. They show that environmental knowledge can affect } \\
\text { absorptive capacity and stimulate the periodical tend by absorbing learning absorptive capacity and } \\
\text { is regulated with nature and competitive field in which the organization is located. They point out } \\
\text { that company regulates different organizational forms with emphasis on different mechanisms to } \\
\text { collect knowledge considering nature of these settings (stable, chaotic etc.). by mentioning that the } \\
\text { previous knowledge is effective on absorptive capacity, they proved that effect on capacity is }\end{array}$ \\
\hline
\end{tabular}




Writer

Minbaeva , 2003

Lane et al, 2006

Arbussà and

Coenders, 2007

Liao et al. 2003

Todorova and

Durisin, 2007

Bergh \& Lim

2008

Harrington \&

Guimaraes, 2005

Cadiz, Sawyer \&

Griffith, 2009

Kallio and

Bergenholtz, 2011

Uotila et al. 2013
Definition

determined through a set of the related mechanisms with organizational forms and studied effect of structures such as performance, part and matrix on absorptive capacity and what they suggest as combinatorial capability indicates the way in which the company acquires knowledge and applies it.

Minbua studies absorptive capacity as ability of the organization to use and apply the previously acquired information and indicates that the specified activities of human resources management will have positive effect on development and improvement of absorptive capacity.

Absorptive capacity refers to one of the main learning processes which means ability to identify, absorb and utilize the environmental knowledge and structure of ability of a company to use the external knowledge by 1 - recognizing and understanding external knowledge through exploratory learning, 2- absorbing new knowledge through transformational learning, 3- use of the absorbed knowledge for creation of new knowledge and commercial outputs through learning of the exploiter.

These writers created changes in definitions of Cohen and Levinthal and also few changes in dimensions. They performed this work by limiting the structure into two dimensions: evaluation, acquisition and absorption of the external knowledge and internal publication and application of the knowledge.

They define absorptive capacity as ability to recognize value of information and new external knowledge, absorb, apply and commercialize information. They argue that when the external knowledge is based on the cognitive structures, absorption occurs and it leads to direct utilization using it. But when the external knowledge is not based on the suitable ideas with the structures of internal knowledge, knowledge and ideas are changed and converted.

Absorptive capacity is an important factor in determination of ability of an organization to obtain and use the external knowledge in its favor and use it in internal procedures and it will be available when it results in higher productivity and internal application of the acquired and absorbed cases leading to a thing beyond the present procedures.

Absorptive capacity is an approach which has three steps: ability to convert new knowledge into the usable knowledge through the processes of evaluation (identifying and filtering valuable information), homogenization (converting new knowledge into usable knowledge ), application (use of knowledge )

Social cohesion mechanism means need for communication between absorptive capacity potential and realization of absorptive capacity to reach the intended goals.

These writers regarded concepts and dimensions presented by Todorova and Darinsen as development and absorptive capacity affected by learning and considered the same classification with a new approach and believes that effect of learning on absorptive capacities is an introduction for innovative actions. 1- Acquiring, absorbing and utilizing leading to incremental innovation and utilization and 2- acquiring, change and utilization relating to the exploratory innovation processes.

\section{Presented model}

To present the model, two methods were used in the research and by reviewing all literatures, dimensions were identified and a primary hypothetical model was presented by classifying it with qualitative method (grounded theory) and it was argued that four steps were corrected in this model that is dimensions and classification were first presented to the experts and the participant were asked questions about dimensions and classification and the corrected, added and deleted dimensions were considered in one step and the classifications were considered in the next step. in the next step, the dimensions which had semantic and conceptual overlap were corrected and one sage was also performed after performing the experimental factor analysis to correct the accruing errors for correcting dimensions and classifications. The selected dimensions and class for absorptive capacity were presented in two Sections: 1- Processes, 2- Capabilities.

\subsection{Processes}

They have been included in three classifications. Unlike the previous models particularly Zahra and George's 4-part model [22], [35] which is the dominant flow in absorptive capacity, the above model has 4 parts which have been included in three classes. The next changes added to the model create two dimensions of keeping and reordering. Variables of the dimensions considered for this index are summarized in three classifications in unlike the previous models particularly Zahra and George's 4-part model [22], [35] which is the dominant flow in absorptive capacity; the above model has 4 parts which have been included in three classes' . Tables. Unlike the previous models particularly 
Zahra and George's 4-part model [22], [35] which is the dominant flow in absorptive capacity, the above model has 4 parts which have been included in three classes.

Table 5: Variables of Dimension of Processes and Index of Exploration

\begin{tabular}{|c|c|}
\hline Researcher & Variables \\
\hline 1- $\quad$ Recognition & \\
\hline Jansen et al. 2005 & Paying attention to search for information \\
\hline Experts' view & Surveying environment for new technologies \\
\hline Experts' view & Observing and expressing technological trends \\
\hline Experts' view & Exploring details of technologies in external sources \\
\hline Experts' view & Informing external technology \\
\hline Acquisition & \\
\hline Caloghirou et al. 2004 & Openness relative to environment \\
\hline Lane et al. 2001 & Competition knowledge \\
\hline Arbussà and Coenders & Internal development of capacities and technological abilities o \\
\hline Veugelers 1999 & Common research projects with the research institutes beyond industry \\
\hline Wilkens et al. 2004 & Exchange of information inside the same industry \\
\hline 3- $\quad$ Absorption & \\
\hline Jansen et al. 2005 & Technology absorption \\
\hline Caloghirou et al. 2004 & Human resources \\
\hline Tu et al. 2006 & Determining industrial criteria \\
\hline Arbussà and Coenders & Participation in knowledge publication \\
\hline Jansen et al. 2005 & Attendance in educational courses \\
\hline Szulanski 1996 & Knowledge management \\
\hline Lu et al. 2006 & Role of a good model in knowledge distribution \\
\hline Gee Woo and Young- & Knowledge sharing \\
\hline Espinosa et al. 2007 & Organizational self-awareness \\
\hline Shu et al. 2005 & Informal communication \\
\hline Ko, Kirsch, and King & Mutual relations for exchange of knowledge, ideation and problem solving \\
\hline Experts' view & Absorbing knowledge from formal and informal professional sources \\
\hline Experts' view & Technological use of external sources \\
\hline Experts' view & Organizing special sessions with foreign partners \\
\hline Bontis et al. 2002 & Regular interactions with foreign institutions for technological knowledge \\
\hline Experts' view & Transfer of technological knowledge in response to technology acquisition opportunities \\
\hline
\end{tabular}

Table 6: Variables of Processes and Index of Change and Utilization

\begin{tabular}{ll}
\hline Researcher & Variables \\
\hline 1- Transfer and change capacity \\
\hline Jansen et al. 2005 & Transfer of knowledge based on information technology \\
Jansen et al. 2005 & Innovation capability \\
Jansen et al. 2005 & Adaptation capacity \\
Soo et al. 2007 & Exchange of scientific and technological information \\
Vinding 2006 & Research and development integration \\
Pavlou and El Sawy & Creating communication between the existing knowledge and new insight \\
Tiwana and McLean & Intelligent use of local and foreign information \\
Collins and Smith & Formation of ideas with cross relations \\
Farrell 2000 & Relationship between learning and competitive learning from the viewpoint of management \\
Hock-Hai et al. 2006 & Means of promoting knowledge to increase competition \\
Hock-Hai et al. 2006 & Involvement of personnel in education and learning \\
Hock-Hai et al. 2006 & Use of knowledge base for increasing insight \\
Liao et al. 2007 & Structuring ability \\
Ettlie and Pavlou & Use of new knowledge in activities \\
Bontis et al. 2002 & Encouraging personnel to produce knowledge \\
Pavlou and El Sawy & Knowledge adaptation capacity \\
Experts' view & Ability to adapt new technologies to idea \\
Experts' view & Rapid recognition of technological utility of the new knowledge \\
Experts' view & Ability of manpower to share their specialty \\
Experts' view & Ability to renew knowledge \\
\hline 2- Application & \\
\hline Jansen et al. 2005 & Utilization of new knowledge \\
Soo et al. 2007 & Use of experience \\
\hline
\end{tabular}




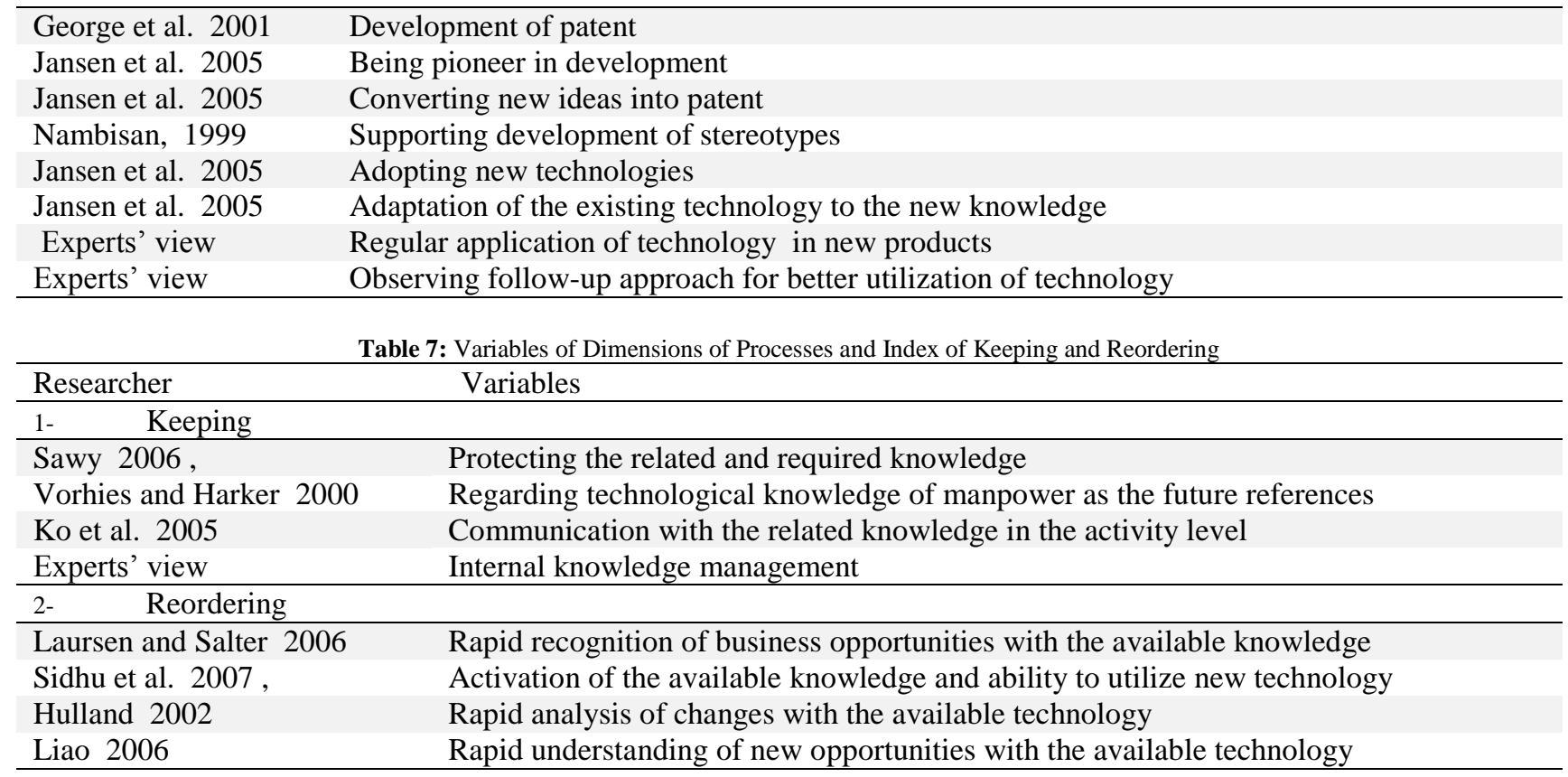

\subsection{Capabilities}

Capabilities are the main part modeled in absorptive capacity section. Considering the conducted studies in the previous models, none of them have the dimension which refers to abilities and competencies. For this reason, this section was considered and this part of model was presented based on view of the experts and the conducted researches. This section includes two general classifications including coordination of collective efforts and capacity of production and transfer of foreign knowledge. In this part of the model, it can be named as research flowing section considering that it is completely new. Since any dimension called capabilities with a concept close to this index was never used in any of the researches on the absorptive capacity and the researches with similar subjects and this index was used with the approach in which a series of capabilities and grounds which are mentioned as capabilities should be available in addition to the process concepts [22], [35].

Table 8: Variables of Capabilities Dimension

\begin{tabular}{l}
\hline $1-\quad$ Intrecational and external capacities \\
\hline Native education \\
Human capitals experience \\
Possessing human capitals \\
Native publication of creativity and innovation \\
Penetrability of economic and social structure \\
Easy native cooperation \\
Naïve strategic orientation \\
Support of general management \\
Interconnected information and knowledge services \\
Collective support and education services for R\&D \\
General environmental coordination \\
Environmental credit \\
\hline 2- Internal capacities \\
\hline Innovative system and culture \\
Proportion of personnel with learning goals \\
Obligation of manpowerdination \\
Managerial support of learning \\
Organizational design for learning \\
R\& D Investment
\end{tabular}




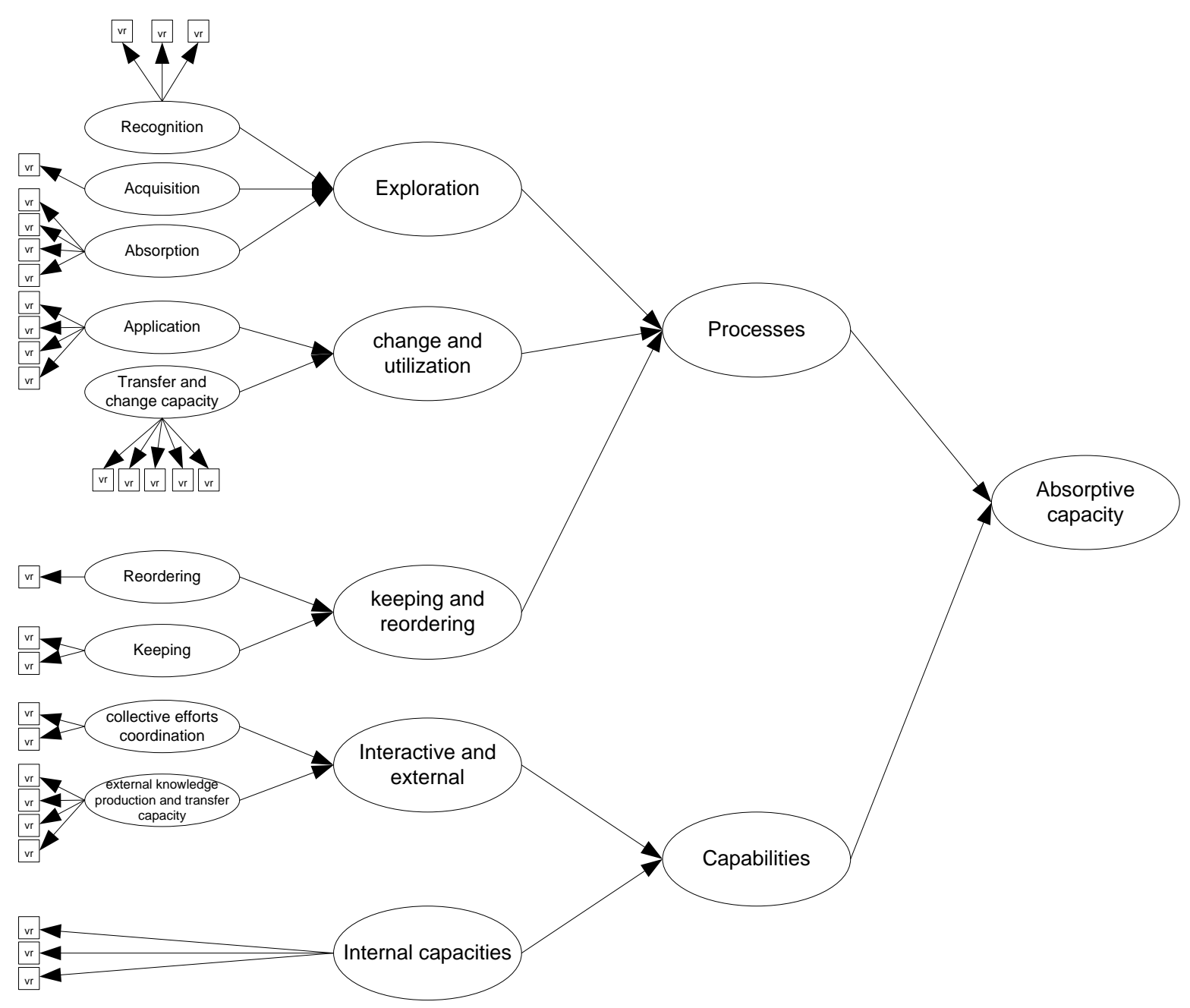

Fig. 1: Absorptive Capacity Model

\section{Research method}

Considering unlimited statistical population in this research, the desirable sample size was calculated with Cochran formula. This number included 267 persons. In this research, to study content validity, attempt was made to use the related questionnaires and then views of the professors and experts were used. The statistical population of the research included experts and players and also B.S and M.S students of technology management and Nano field and also companies involved in nanotechnology. The research was conducted in three steps:

First step: Design of the initial model with qualitative method grounded theory: the used instrument included study of the documents and the statistical population included all papers and information.

Second step: The model validation step with qualitative method focus group: the used instrument was interview and the sampling method was snowball sampling method.

Third step: surveying and revising the model with survey quantitative method. To design of the model, SEM has been used. The used instruments are SPSS software and LISREL.

\section{Validity and Reliability}

Validity: Attempt has been made to use the related questionnaires and then views of the professors and experts were also used. The exploratory factor analysis was also used to study construct validity. Regarding the proposed model, the model was improved with stepwise method.

Reliability: In the research, Cronbach's alpha was calculated in two steps. After collecting 30 initial questionnaires, results show that the research instrument has enough reliability and Cronbach's alpha was calculated 0.92 indicating high reliability and in the second step, the test was studied against after collection of the questionnaires.

Initial study of data: The number of outliers was 7 data with elimination method and the $\mathrm{D}^{\wedge} 2$ probability function value has been used. 6 cases of the observations relating to the dependent variable and 4 cases of the independent variables were excluded 1 reverse item was also observed. 
Table 9: Study of Data

\begin{tabular}{llllllll}
\hline \multicolumn{7}{c}{ Low skewness limit : 0.038} & \multicolumn{7}{c}{ High skewness limit : -0.59 } \\
\hline \multicolumn{2}{l}{ Low kurtosis limit : -0.91} & \multirow{7}{c}{ Tabh kurtosis limit : 0.346} \\
\hline Kurtosis error & Kurtosis & Skewness standard error & Skewness & Standard & Mean & Median & Statistic \\
0.314 & -0.282 & 0.157 & -0.276 & 1.5 & 3.33 & 3.23 & Value \\
\hline
\end{tabular}

\section{Results of factor analysis}

The first step is recognition of performing factor analysis on the data. Bartlett test, KMO test: In the first rank exploratory factor analysis, KMO is equal to 0.718 for 29 items relating to the absorptive capacity variable which indicates that the research data are reduced to some infrastructural and fundamental factors. The second step is recognition of share of factor set in explaining variance of any item. Here, variance of any item is specified based on table of similarities which includes initial value which is always equal to 1 and the extracted value which any item could explain is higher than acceptable limit of 0.4 for all items and the third step is recognition of share of each factor in explanation of sum of variance of all items based on literature. 10 factors have been defined as dimensions of absorptive capacity variable. At the same time, 9 factors have eigenvalue of above 1 and the next step has eigenvalue of close to 1 . Sum square roots of the rotated factor loads also show the explained variance. These 10 factors explain about $80 \%$ of the absorptive capacity variable changes. At the end, in the fourth step i.e. recognition of correlation matrix between items and factors and classification of any item in each factor, results of the rotated table should be used to classify the items among factors based on their factor load. This Table shows correlation between items and factors after rotation in which correlation value fluctuates in \pm 1 . At the end, the following Table indicates the obtained dimensions and their naming.

Table 10: Initial Classification of Dimensions and Their Naming

\begin{tabular}{llllll}
\hline Factor & Questions & Naming & Factor & Questions & Naming \\
\hline 1 & 14 to 17 & Absorption & 6 & 21 to 25 & Change \\
2 & $1 \& 2$ & Collective efforts coordination & 7 & 3 to 6 & Production capacity \\
3 & 26 to 29 & Utilization & 8 & 7 to 9 & Internal capacity \\
4 & 18 to 19 & Keeping & 9 & $20 \& 21$ & Reordering \\
5 & $10 \& 11$ & Recognition & 10 & $12 \& 13$ & Acquisition \\
\hline
\end{tabular}

\section{Final classification of dimensions}

In the next step, we repeat the previous steps for summary to specify if a new classification can be obtained for the dimensions. Therefore, it is necessary to perform the performed steps and tests for the extracted classification and dimensions in the previous step. According to Table of step 3, it was specified that 10 extracted Factors from the first rank of the absorptive capacity can be classified into 5 general factors. Based on Table of the rotated factors, it can be specified which factors form dimension or component with each other.

Table 11: Secondary Classification of Dimensions and Naming Then In the Second Step

\begin{tabular}{lll}
\hline Dimensions & Indices & Name \\
\hline 1 & Keeping and reordering & Keep \\
2 & Change and utilization & Change \\
3 & Absorbing, acquiring and cognition & Explore \\
4 & Collective efforts coordination, production capacity & Interactional competencies \\
5 & Internal capacities & Internal capacities \\
\hline
\end{tabular}

\section{Pearson correlation}

Before executing structural equation model, it is better to study relation of variables based on correlation. Considering that data are in interval level and also data distribution follows normal form. Therefore, Pearson correlation coefficient has been used to measure intensity and significance of the relations. Before determining and interpreting correlation coefficient, it is better to study scatter diagram of the binary relations of the variables graphically. This diagram shows linearity or non-linearity, intensity and type of relation direct or reverse. Whenever scattering of the points increases, correlation coefficient will be reduced. Scattering diagram of these two variables is given in the following Figure. The line which has been drawn between the points is correlation or regression line. 
Table 12: Table of Mean of Variables

\begin{tabular}{lll}
\hline Variable & Mean & Standard deviation \\
\hline Absorptive capacity & 3.3 & 0.32 \\
\hline
\end{tabular}

\section{Studying the structural model}

In the model structural section, relations among the internal and external hidden variables are considered. Here, theoretical relations among the variables in formulation of the framework will be studied to see if it has suitable fitness. On the other hand, significance of the relations is tested in this fitted model.

Since general execution of the model is not possible in Lisrel software, we study the model in two levels separately.

Table 13: Analysis First Level Indices

\begin{tabular}{llllll}
\hline Indices & DF & CFI & GFI & AGFI & SRMR \\
\hline First model & 159 & $0 / 89$ & $0 / 81$ & $780 /$ & $0540 /$ \\
\hline
\end{tabular}

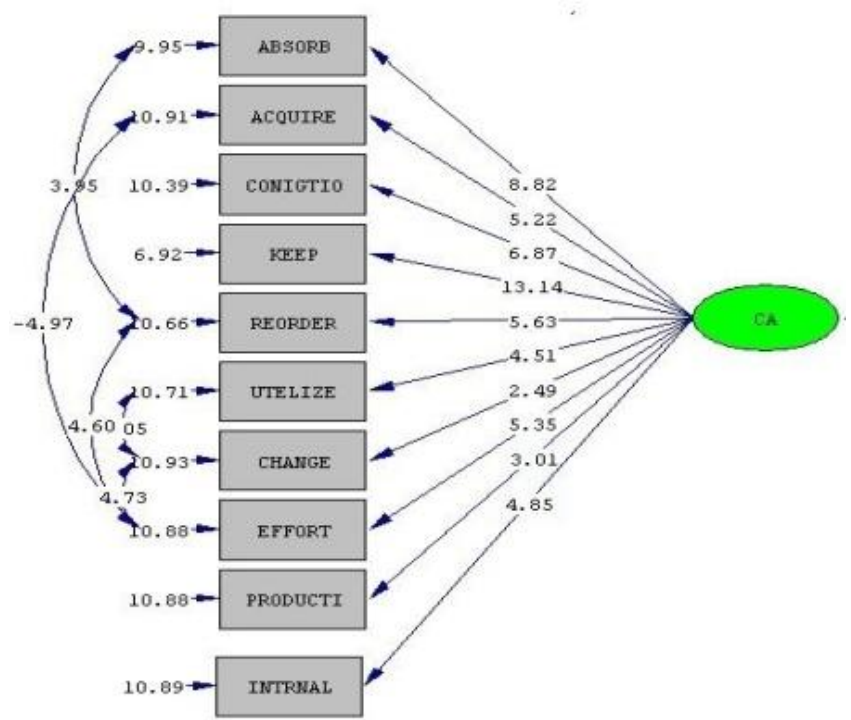

Fig. 2: Significance of the First Structural Model

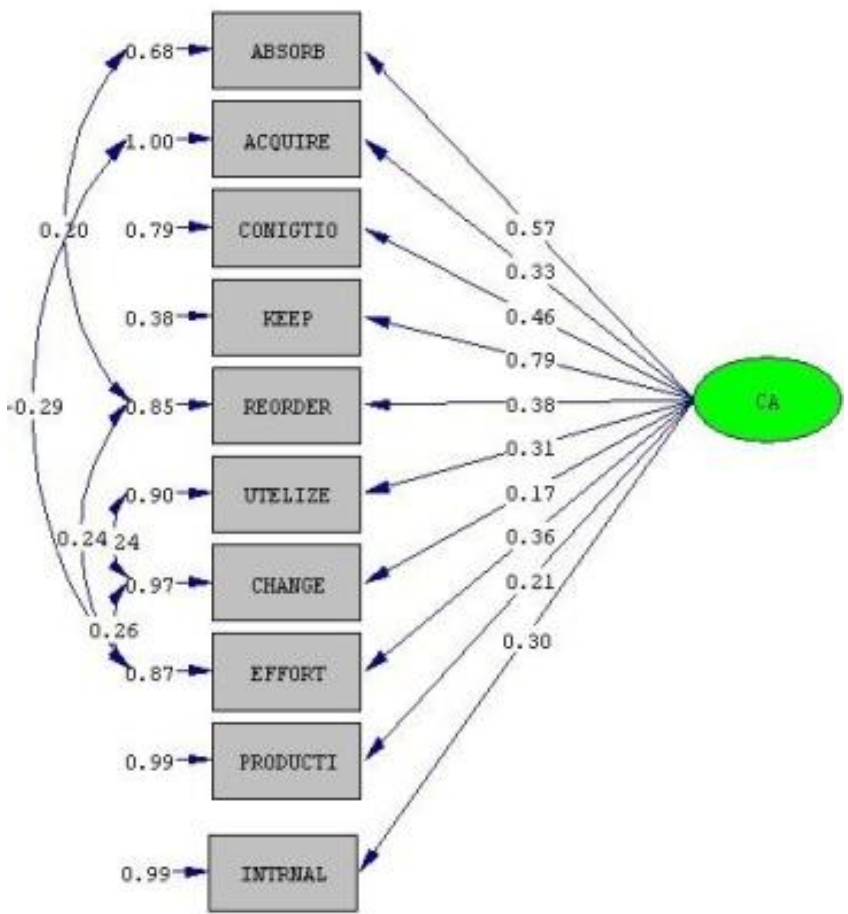

Fig. 3: Standard Factor Loads of the First Structural Model 
Table 14: Coefficients and Priorities of the First Structural Model

\begin{tabular}{|c|c|c|c|}
\hline \multicolumn{4}{|l|}{ Absorptive capacity } \\
\hline Index & Coefficient priority & Index & Coefficient priority \\
\hline Keep & 0.79 & Acquire & 0.33 \\
\hline Absorb & 0.57 & Utilize & 0.31 \\
\hline Cognition & 0.46 & internal capacity & 0.3 \\
\hline Collective efforts coordination & 0.36 & Production capacity & 0.21 \\
\hline Reorder & 0.36 & Change & 0.17 \\
\hline
\end{tabular}

In the second level, with factor analysis, we will study what dimensions are used for classification of dimensions and the results can be observed. In this model, we study dimensions of the main variable. We first study fitting indices. These indices have been obtained after corrections of the covariance errors. The fitting indices can be observed in the Table. Considering fitting indices, relative chi-square value is below 3 and CFI 'GFI 'AGFI and SRMR are also standard. Therefore, fitness of the model can be confirmed.

Table 15: Analysis First Level Indices

\begin{tabular}{llllll}
\hline Indices & DF & CFI & GFI & AGFI & SRMR \\
\hline First model & 23 & 0.88 & 0.91 & 0.83 & 0.020 \\
\hline
\end{tabular}

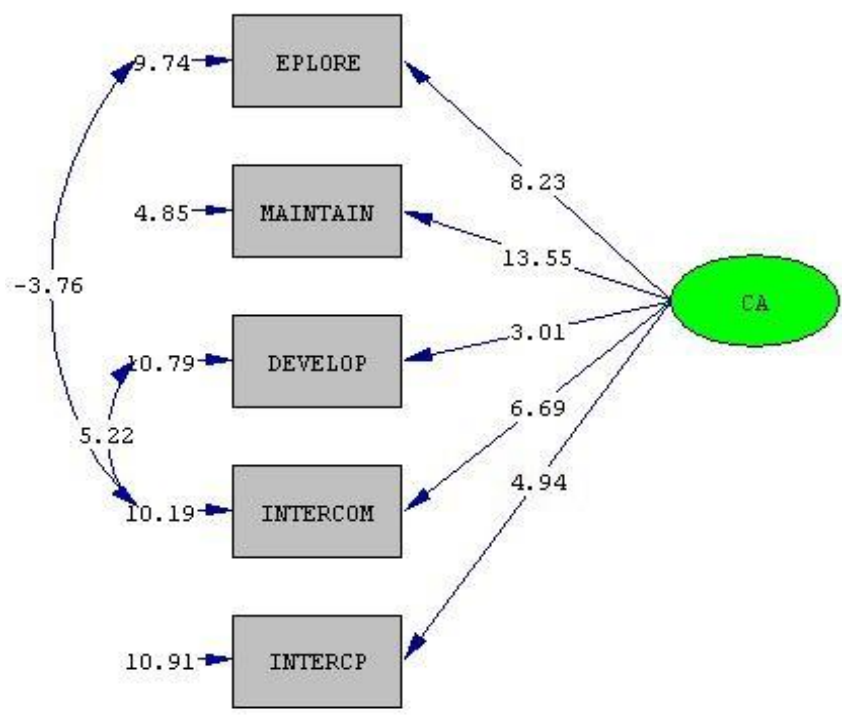

Fig. 4: Significance Numbers of the First Structural Model

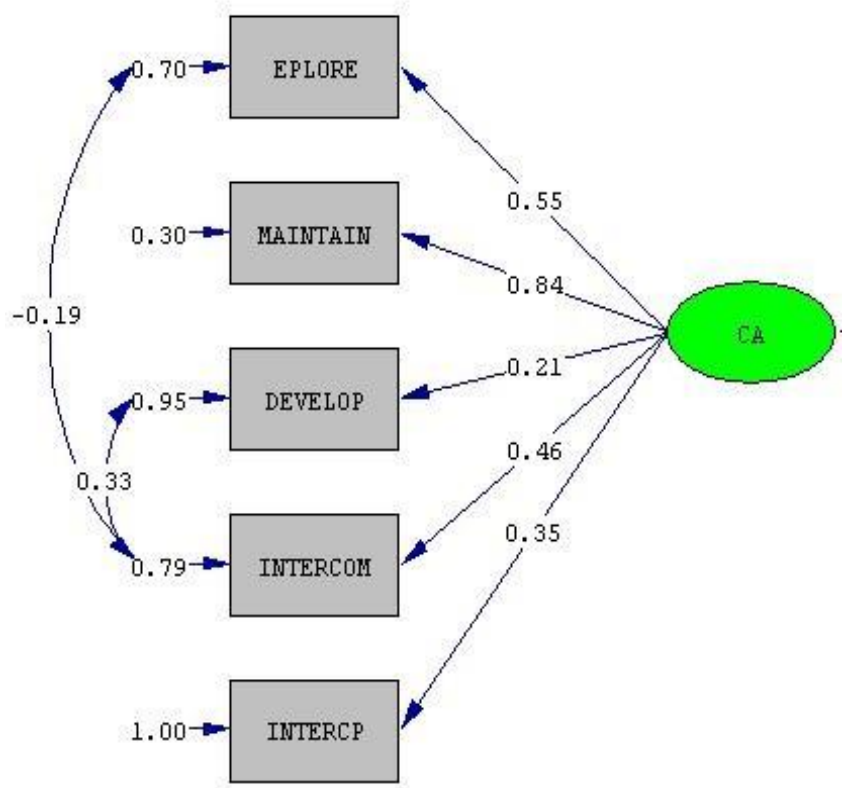

Fig. 5: Standard Factor Loads of the Second Structural Model 
Table 16: Prioritizing Coefficients in the Second Order Exploration

\begin{tabular}{lc}
\hline Factor & priority \\
\hline Keep & 0.84 \\
Explore & 0.55 \\
Interactional competencies & 0.46 \\
Internal capacities & 0.35 \\
Change & 0.21 \\
\hline
\end{tabular}

Considering the Table, it is evident that the largest coefficient belongs to keeping dimension and has the highest priority in prioritization; therefore, keeping index has the highest significance in this model considering the conducted studies and factor analysis. Thus, it can lead to policymaking and process making in the studied fields.

\section{Conclusion}

Learning is the first step and main factor in innovation and increase of competitiveness. Learning occurs when there is correct understanding of the environmental data and necessary capacity for receiving these data can be created. Absorptive capacity is an effective concept which leads to understanding of managerial activities and utilization of technologies and ability to make effective innovation. Absorptive capacity creates opportunities for innovation or reduces limitations of the internal combination of knowledge sources in an innovation model. Statement of this issue is a primary step for finding the root of the problem which the third world countries and developing countries have faced and that is dream of development. This puzzle is the root of many studies conducted in the past and many models for justification and statement of successful of the countries which could pass the way of development in short term. The researchers have documented and modeled the ways which this group of agencies has passed more comprehensively so that they can present a comprehensive and usable version. The present research can help find the lost circle of the hightech industries particularly nanotechnology which led to low productivity of the said industries and slower growth and development speed than that of the pioneers considering special time conditions and situation of the country. As mentioned above, the main goal of this research is to identify factors of absorptive capacity.

At the beginning of the research, considering the absence of literatures in the country and newness of the research subject, the only way for defining the subject and identifying main factors is to refer to the internationally conducted studies. Then, attempt was made to identify and introduce main effective factors while providing comprehensive definition as far as possible. In the internationally provided definitions, absorptive capacity is defined as ability to recognize value of new things, external information, absorb, adapt and apply them is important and vital for commercial purposes for the innovation activities and focus was on this definition though many definitions were changed . For this purpose, attempt was made to present hidden layers, new factors and new definitions by studying research flows which had high overlap with the absorptive capacity in terms of dimensions and concepts. For this purpose, there was focus on key words of the absorptive capacity. In addition to the mentioned issues, concept of the absorptive capacity was studied in two fields. The first field included concepts of measurement and the second field included effective dimensions and finally, attempt was made to present a comprehensive model with literature and experts' view. In this research, new concepts were presented in the field of absorptive capacity. In the previous researches, we could include what was mentioned for absorptive capacity in classification of the processes meaning that all mentioned factors focused on the index which was regarded as process in terms of concept and nature and the main focus was on the set and structure. It was mentioned that it might be importance of the set or country but if there is need for any change, the internal changes should be made by correcting the processes. This process might be related to the inside and outside of the set. But a new concept was presented in this research which was named capabilities and this new concept changed the previous classifications in the field of absorptive capacity. A concept called processes was not referred before and this classification was presented to show substantial difference of the effective factors.

By studying the provided model which was extracted from conclusion of the materials and the conducted factor analysis, dimensions were included in 5 general classes including: 1-keeping, 2-exploration, 3-interactional competencies, 4-internal capacities, and 5-change. As the analyses showed, the factors were had the largest coefficient were keeping and reordering which consisted of two parts: 1- keeping and maintaining and 2-activating and reordering. Dimensions and indices can be resented for the said variable. It is worth noting that the mentioned indices have been prepared from the documents such as vision 1404 and the mentioned cases are among the main indices relating to the mentioned dimensions in the field of nanotechnology of Iran according to the experts and during interview with specialists and experts.

\section{a) Keeping:}

- $\quad$ Protecting the related and required knowledge

- $\quad$ Regarding the technological knowledge approach of manpower as the future references

- $\quad$ Communication with the related knowledge in the activity level

- Internal knowledge management

\section{b) Reordering}

- Rapid recognition of business opportunities with the available knowledge 
- Activation of the available knowledge and ability to utilize new technology

- $\quad$ Rapid analysis of changes with the available technology

- $\quad$ Rapid understanding of new opportunities with the available technology

\section{Acknowledgements}

The authors appreciate the editors and reviewers for their comments that lead to improve the quality of the paper.

\section{References}

[1] M. Moradi M, Abdolhian, F. Safar Doost. Studying role of knowledge absorptive capacity in relationship between learning of the organizational errors and organizational innovation..

[2] Cohen WM, Levinthal DA. Absorptive capacity: a new perspective on learning and innovation. Administrative science quarterly. 1990:12852. http://dx.doi.org/10.2307/2393553.

[3] Zahra SA, George G. Absorptive capacity: A review, reconceptualization, and extension. Academy of management review. 2002 ; 27 2:185203

[4] Bakar AHA, Tufail MA. Transforming Capability of Indigenous Contractors through Technology Transfer: A Malaysia Experience. World Applied Sciences Journal. 2012; 16 10:1450-61.

[5] Lin C, Tan B, Chang S. The critical factors for technology absorptive capacity. Industrial Management \& Data Systems. $2002 ; 102$ 6:300-8. http://dx.doi.org/10.1108/02635570210431993.

[6] Rahmanani, creating absorptive capacity fort organizing open innovation in SME. The fourth national conference of Iran technology management.

[7] Schilling MA. Strategic management of technological innovation: McGraw-Hill/Irwin New York; 2005.

[8] Uotila T, Harmaakorpi V, Melkas H. A method for assessing absorptive capacity of a regional innovation system. Fennia-International Journal of Geography. 2006; 184 1:49-58.

[9] Moos B, Beimborn D, Wagner H-T, Weitzel T. Knowledge Management Systems, Absorptive Capacity, and Innovation Success. 2011.

[10] Teece DJ, Pisano G, Shuen A. Dynamic capabilities and strategic management. 1997.

[11] Chiva R, Alegre J. Organizational Learning and Organizational Knowledge towards the Integration of Two Approaches. Management learning. 2005; 36 1:49-68. http://dx.doi.org/10.1177/1350507605049906.

[12] Cadiz D, Sawyer JE, Griffith TL. Developing and validating field measurement scales for absorptive capacity and experienced community of practice. Educational and Psychological Measurement. 2009; 69 6:1035-58. http://dx.doi.org/10.1177/0013164409344494.

[13] Indarti N. The Effect of Knowledge Stickiness and Interaction on Absorptive Capacity. 2010.

[14] M. Haji K, Haji Poor Designing measurement model of knowledge absorptive capacity: case study of State Pharmaceutical Industries.

[15] Schmidt T. Absorptive Capacity-One size fits all? A Firm-level analysis of absorptive capacity for different kinds of knowledge. A firm-level analysis of absorptive capacity for different kinds of knowledge. 2005:05-072.

[16] Lichtenthaler U. Technology exploitation in the context of open innovation: finding the right 'job'for your technology. Technovation. 2010; 30 7:429-35. http://dx.doi.org/10.1016/j.technovation.2010.04.001.

[17] Jiménez-Barrionuevo MM, García-Morales VJ, Molina LM. Validation of an instrument to measure absorptive capacity. Technovation. 2011; 31 5:190-202. http://dx.doi.org/10.1016/j.technovation.2010.12.002.

[18] Fabrizio KR. Absorptive capacity and the search for innovation. Research Policy. 2009;38 2 :255-67. http://dx.doi.org/10.1016/j.respol.2008.10.023.

[19] Dahlander L, Gann D, editors. Appropriability, proximity, routines and innovation: How open is open innovation. DRUID summer conference; 2007.

[20] Giuliani E. Cluster absorptive capacity why do some clusters forge ahead and others lag behind? European Urban and Regional Studies. 2005; 12 3:269-88. http://dx.doi.org/10.1177/0969776405056593.

[21] Escribano A, Fosfuri A, Tribó JA. Managing external knowledge flows: The moderating role of absorptive capacity. Research Policy. 2009; 38 1:96-105. http://dx.doi.org/10.1016/j.respol.2008.10.022.

[22] Camisón C, Forés B. Knowledge absorptive capacity: new insights for its conceptualization and measurement. Journal of Business Research 2010; 63 7:707-15. http://dx.doi.org/10.1016/j.jbusres.2009.04.022.

[23] Gebauer H, Worch $\mathrm{H}$, Truffer B. Absorptive capacity, learning processes and combinative capabilities as determinants of strate gic innovation. European Management Journal. 2012; 30 1:57-73. http://dx.doi.org/10.1016/j.emj.2011.10.004.

[24] Colombo M, Foss N, Rossi-Lamastra C. Organizational design for absorptive capacity linking individual and organizational levels. MIMEO, 2012.

[25] Van Den Bosch F, Van Wijk R, Volberda HW. Absorptive capacity: Antecedents, models and outcomes. 2006

[26] Castillo LL, Salem DS, Guasch JL. Innovative and Absorptive Capacity of International Knowledge. Policy Research Working Paper No. 2012; 5931

[27] Nieto M, Quevedo P. Absorptive capacity, technological opportunity, knowledge spillovers, and innovative effort. Technovation. $2005 ; 25$ 10:1141-57. http://dx.doi.org/10.1016/j.technovation.2004.05.001.

[28] Grimpe C, Sofka W. Search patterns and absorptive capacity: Low-and high-technology sectors in European countries. Research Policy. 2009; 38 3:495-506. http://dx.doi.org/10.1016/j.respol.2008.10.006.

[29] Lin C, Wu Y-J, Chang C, Wang W, Lee C-Y. The alliance innovation performance of R\&D alliances - the absorptive capacity perspective. Technovation. 2012; 32 5:282-92. http://dx.doi.org/10.1016/j.technovation.2012.01.004

[30] Flatten TC, Engelen A, Zahra SA, Brettel M. A measure of absorptive capacity: Scale development and validation. European Management Journal. 2011; 29 2:98-116. http://dx.doi.org/10.1016/j.emj.2010.11.002.

[31] Feeny S, de Silva A. Measuring absorptive capacity constraints to foreign aid. Economic Modelling. $2012 ; 29$ 3:725-33. http://dx.doi.org/10.1016/j.econmod.2012.01.013.

[32] Kostopoulos K, Papalexandris A, Papachroni M, Ioannou G. Absorptive capacity, innovation, and financial performance. Journal of Business Research. 2011; 64 12:1335-43. http://dx.doi.org/10.1016/j.jbusres.2010.12.005.

[33] Omar R, Takim R, Nawawi AH, editors. Measuring absorptive capacity in technology transfer TT projects. Business Innovation and Technology Management APBITM, 2011 IEEE International Summer Conference of Asia Pacific; 2011: IEEE. http://dx.doi.org/10.1109/APBITM.2011.5996349. 
[34] Delmas M, Hoffmann VH, Kuss M. Under the tip of the iceberg: Absorptive capacity, environmental strategy, and competitive advantage. Business \& Society. 2011; 50 1:116-54. http://dx.doi.org/10.1177/0007650310394400.

[35] Liao S-H, Fei W-C, Chen C-C. Knowledge sharing, absorptive capacity and innovation capability: an empirical study of Taiwan's knowledgeintensive industries. Journal of Information Science. 2007; 33 3:340-59. http://dx.doi.org/10.1177/0165551506070739.

\section{Appendix}

Table 17: The First Step Bartlett's Test

\begin{tabular}{lll}
\hline KMO and Bartlett's Test & & \\
\hline Kaiser-Meyer-Olkin Measure of Sampling Adequacy. & & 0.718 \\
& Approx. Chi-Square & 2179 \\
Bartlett's Test of Sphericity & Df & 406 \\
& Sig. & 0 \\
\hline
\end{tabular}

Table 18: Recognizing Share of Each Factor in Explanation of Sum of Variance of Items in the First Step

\begin{tabular}{|c|c|c|c|c|c|c|}
\hline \multicolumn{7}{|c|}{ Total Variance Explained } \\
\hline \multirow{2}{*}{ Component } & \multicolumn{3}{|c|}{ Initial Eigenvalues } & \multicolumn{3}{|c|}{ Rotation Sums } \\
\hline & Total & $\%$ of Variance & Cumulative \% & Total & $\%$ of Variance & Cumulative\% \\
\hline 1 & 5.805 & 20.018 & 20.018 & 3.333 & 11.493 & 11.493 \\
\hline 2 & 3.277 & 11.301 & 31.32 & 2.613 & 9.009 & 20.501 \\
\hline 3 & 2.653 & 9.147 & 40.467 & 2.608 & 8.994 & 29.496 \\
\hline 4 & 2.505 & 8.637 & 49.104 & 2.6 & 8.965 & 38.461 \\
\hline 5 & 2.105 & 7.258 & 56.362 & 2.392 & 8.247 & 46.708 \\
\hline 6 & 1.952 & 6.732 & 63.094 & 2.171 & 7.485 & 54.193 \\
\hline 7 & 1.632 & 5.627 & 68.721 & 2.121 & 7.313 & 61.506 \\
\hline 8 & 1.275 & 4.396 & 73.117 & 1.966 & 6.778 & 68.284 \\
\hline 9 & 1.198 & 4.13 & 77.247 & 1.957 & 6.75 & 75.034 \\
\hline 10 & 0.956 & 3.296 & 80.543 & 1.598 & 5.51 & 80.543 \\
\hline 11 & 0.724 & 2.497 & 83.04 & & & \\
\hline 12 & 0.712 & 2.455 & 85.495 & & & \\
\hline $13-29$ & - & - & - & & & \\
\hline \multicolumn{7}{|c|}{ Extraction Method: Principal Component Analysis. } \\
\hline
\end{tabular}

Table 19: Second Rank Rotated Matrix

KMO and Bartlett's Test

\begin{tabular}{|c|c|c|}
\hline \multicolumn{3}{|c|}{ KMO and Bartlett's Test } \\
\hline Kaiser-Meyer-Olkin Measure of Sampling Adequacy. & 0.67 \\
\hline \multirow{3}{*}{ Bartlett's Test of Sphericity } & Approx. Chi-Square & 383.5 \\
\cline { 2 - 3 } & df & 45 \\
\cline { 2 - 4 } & Sig. & 0 \\
\hline
\end{tabular}

Table 20: Recognizing Each Factor In Explaining Sum Of Variance Of The Second Step Items

\begin{tabular}{|c|c|c|c|c|c|c|}
\hline \multicolumn{7}{|c|}{ Total Variance Explained } \\
\hline \multirow{2}{*}{ Component } & \multicolumn{3}{|c|}{ Initial Eigenvalues } & \multicolumn{3}{|c|}{ Rotation Sums } \\
\hline & Total & $\%$ of Variance & Cumulative \% & Total & $\%$ of Variance & Cumulative \% \\
\hline 1 & 2.544 & 25.436 & 25.436 & 2.005 & 20.05 & 20.05 \\
\hline 2 & 1.506 & 15.057 & 40.492 & 1.665 & 16.648 & 36.697 \\
\hline 3 & 1.417 & 14.17 & 54.662 & 1.343 & 13.434 & 50.131 \\
\hline 4 & 1.326 & 1.326 & 63.92 & 1.149 & 11.492 & 61.623 \\
\hline 5 & 1.192 & 1.192 & 71.837 & 1.021 & 10.215 & 71.837 \\
\hline 6 & 0.759 & 7.592 & 79.429 & & & \\
\hline $7-10$ & - & - & - & & & \\
\hline \multicolumn{7}{|c|}{ Extraction Method: Pri } \\
\hline
\end{tabular}

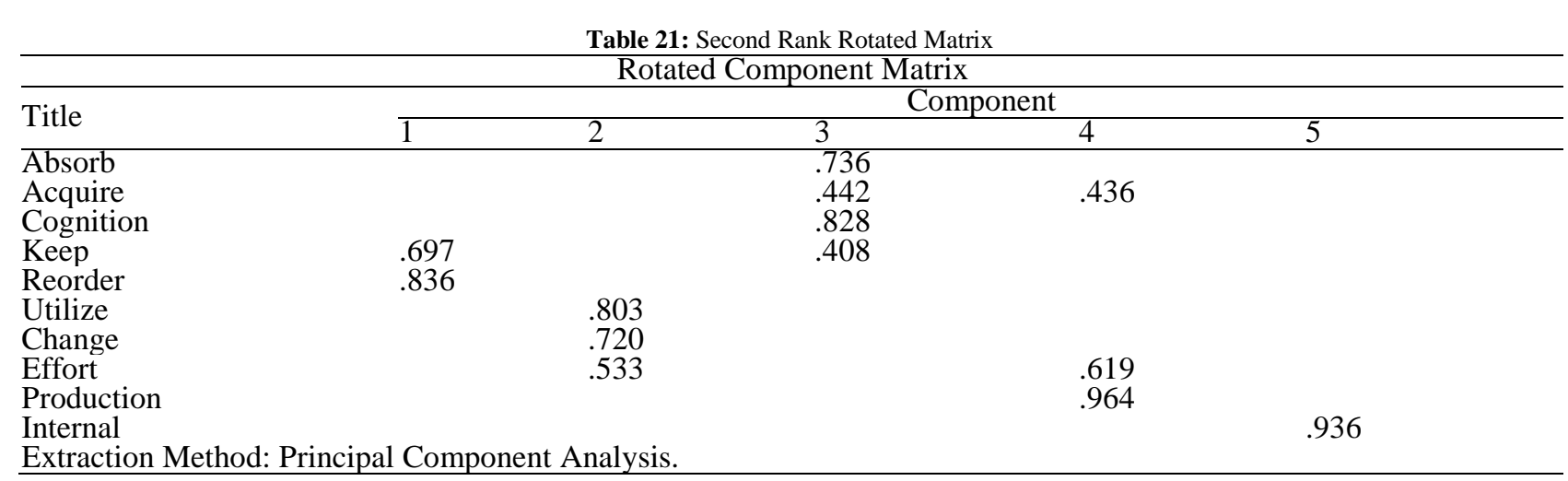

